\title{
THE GREAT MOVE TOWARDS OPENNESS IN ADOPTION
}

\author{
by N Da Rocha*
}

\section{Introduction}

Many noteworthy changes have occurred in South African adoption law in the recent past: With the enactment of the Children's Act, ${ }^{1}$ various new concepts have been provided for. A post-adoption agreement is one such concept. ${ }^{2}$ This provision allows the Children's Court to grant an order confirming an agreement whereby the biological parent/s or guardian/s of a child would have the benefit of either communication or contact with the adopted child, or the right to be provided with certain information concerning such child.

An application for judicial approval of a post-adoption agreement is brought before the court simultaneously alongside the adoption order. This is a major step towards the concept widely known in the international community as 'openness' in the adoption process, and away from the secrecy which dominated adoptions in the past.

Currently in South Africa, adoption may be described as an '.. order [which] has the effect of creating a legal relationship between the adoptive parent and the adopted child in the interests of the child. ${ }^{3}$ This involves the severing of legal ties between the birth parents and their child, relinquishing all parental rights and responsibilities and handing them over to the adoptive parents. Therefore in the eyes of the law, the adopted child is, for all purposes, the child of the adoptive parent/s.

Due to the fact that this is the first time the South African legislature has sought to provide for and regulate post-adoption contact, this article serves as an exploration into the new possibilities and struggles South Africa may face in this regard.

\section{The adoption spectrum}

As explained by the American governmental department of Child

Nicole Da Rocha, fourth year LLB student, University of Pretoria.

Act 38 of 2005 ('the Act').

Provided for in s 234 of the Act.

A Louw 'Adoption of children' in T Boezaart (ed) Child law in South Africa (2009) 133. 
Welfare, open adoption is the opportunity granted to adoption parties whereby they '... allow adoptive parents, and often the adopted child, to interact directly with birth parents. ${ }^{4}$ In a publication by the same department five years later, this definition was extended to include not only birth parents but also '... other persons with whom the child has an established relationship ...'.5

Interaction or contact can take place in various forms and to various degrees. We can therefore view adoption as a spectrum of diverse options. On the one end of the adoption spectrum we have completely confidential (closed) adoptions, while to the opposite end of the spectrum we have what we may refer to as fully disclosed (open) adoptions. ${ }^{6}$ In the middle of this scale are mediated (semiopen) adoptions.

The degree to which an adoption will be open depends completely on the parties to the adoption. The various degrees of openness enable '... family members to interact in ways that feel most comfortable to them.'

Before an adoption order is made, merely allowing the adoptive parent to be involved in the selection process for adoptive parents without any further contact with them or the child given up for adoption thereafter, is considered a form of open adoption practice. ${ }^{7}$ The biological parent is given particular identifying information about the prospective adoptive parents in order to make the decision. ${ }^{8}$ Similarly, prospective adoptive parents who receive medical information (particularly medical history) from a birth parent prior to an adoption, generally with the aim of wanting to be fully informed with regard to a child they may adopt, also exercise a form of open adoption practice. ${ }^{9}$

Mediated (semi-open) adoptions occur where parties consent to the exchange of information relating to the adoptee but do not wish to have direct contact occur between the birth parent/s and the adoptee. The information is then relayed to the particular party via a mediator (such as an attorney or social worker). ${ }^{10}$ The parties in this case may agree to what type of information is exchanged.

4 http://www.childwelfare.gov/pubs/f_openadoptbulletin.cfm (accessed 6 July 2010).

5 www.childwelfare.gov/systemwide/laws_policies/statutes/cooperative.cfm (accessed 6 July 2010).

6 As above.

7 L Gaddie 'Open adoption' (2009) 22 Journal of the American Academy of Matrimonial Lawyers 499.

8 www.childsafety.qld.gov.au/legislation/documents/consult-chap04.pdf (accessed 1 August 2010).

9 http://adc.bmj.com/content/95/1/7.extract (accessed 1 August 2010).

10 n 5 above. 
The exchange of information may be regulated by an agreement such as the one envisaged in section 234(1)(b) of the Act, and therefore can continue to take place long after the adoption order is granted. Since this section does not specify whether such an exchange should take place via a mediator or directly between the parties, this is a point which should be agreed upon by the parties themselves.

Post-adoption communication between the adoptive family and birth relatives may occur in a number of ways - they may agree to the exchange of letters, e-mails and telephone calls, or consent to the granting of visitation rights. ${ }^{11}$ The parties also agree to how frequent communication may take place. This is what the legislature has provided for in section 234(1)(a) of the Children's Act.

When parties are in the process of negotiating the parameters of an adoption order, they must take into consideration the needs and wishes of all parties involved. Paramount to all this however is the best interests ${ }^{12}$ of the adoptee, a standard entrenched by the South African Constitution.

A post-adoption contract therefore, is concluded by the parties to an adoption for the purpose of specifying the type and frequency of contact after the adoption order is granted..$^{13}$ One must not make the error in thinking that open adoption creates a 'shared care' or joint care arrangement between adoptive parents and birth parents ${ }^{14}$ - since an adoption, no matter how open it is, still results in the total relinquishment of the birth parents' parental rights and responsibilities. ${ }^{15}$

\section{Why encourage open adoption practice?}

The ultimate purpose for concluding a post-adoption agreement is to contribute to the success of the adoption ${ }^{16}$ by recognising what is best for the wellbeing of the child and simultaneously making an effort to cater for the other parties' interests as far as reasonably possible. Open adoption therefore, does not describe a single practice or refer to only one part of the adoption process.

The government of Queensland, a state of Australia, conducted an extensive investigation beginning in 2002 in an effort to ascertain the best adoption practices in Australia and from around the world. The

1 n 5 above.

$12 \mathrm{Sec} 28$ of the Constitution of the Republic of South Africa, 1996 ('the Constitution').

n 5 above.

n 7 above, 499.

n 3 above, 133.

www.childsafety.qld.gov.au/legislation/documents/future-adoption-laws.pdf (accessed 3 September 2010). 
investigation concluded with numerous reasons for legislating in favour of open adoptions. ${ }^{17}$

Firstly, open adoption practice takes cognisance of the fact that adoption does not result in the removal of the existence of children's birth parents from their lives. Rather, it recognises that adoptees have birth parents as well as adoptive parents. Open adoption practices may consequently be utilised as a mechanism to ensure that the interests of both sets of parents attain equal respect in the adoption process.

The investigation also highlighted the fact that adoption results in children having one set of legal parents, namely their adoptive parents. It is an important fact to remember:

Adoption results in the severance of legal ties between the adoptee and birth parent, the fact that an adoption is open and subject to a postadoption agreement does not create a joint care arrangement between adoptive parents and birth parents.

An exceptionally important revelation surfacing from the investigation is that children benefit from knowing about their birth parents and the circumstances of their adoption. This fact will undoubtedly lend to the increase in utilisation of open adoption practices since the welfare of the child is the paramount concern.

Much research has been conducted in order to ascertain the effects of open adoptions on the parties to the adoption arrangement. Research shows that many fears regarding open adoption are merely based on myths. The results obtained by the American Child Welfare governmental department in this respect will now be briefly discussed. ${ }^{18}$

It has been found that parties in fully disclosed adoptions are not confused about their parenting rights and responsibilities and therefore adoptive parents in open adoptions do not feel less in control but rather have a healthy sense of permanence in their relationship with their child. Likewise, the adoptee is not confused about who his or her parents are - research shows that children understand the different roles of adoptive and birth parents in their lives.

The research also states that 'open adoption does not interfere with adoptive parents' sense of entitlement or sense that they have the right to parent their adopted child ...' and contrary to widely held assumptions, birth mothers do not attempt to 'reclaim' their children. 
American child welfare experts profess that full disclosure does not appear to influence an adoptee's self-esteem in any negative way and '... birth mothers in open or ongoing mediated adoptions do not have more problems with grief resolution; indeed, they show better grief resolution than those in closed adoptions. ${ }^{19}$

With the welcoming of open adoption practices in South Africa comes a range of flexible options available to persons involved in an adoption. It enables parties to agree on an adoption plan which they may specifically tailor to meet the needs and wishes of all relevant people as far as possible.

By disclosing medical information for example, it allows the adoptive parents to make an informed choice as to the child they will be parenting; enabling them (and the adoptee) to be somewhat prepared for any current or future health risks the child may carry. ${ }^{20}$ The fact that family history is a central enquiry in any paediatric consultation reminds us of the importance of full medical disclosure.

From the adoptee's perspective, a lack of knowledge about her birth family's medical history leaves a significant gap in her future understanding of her own personal health risks. ${ }^{21}$ Therefore it seems it would be quite beneficial for the persons involved that it should become standard practice to encourage at the very least, full disclosure of medical information by the birth family.

The Constitution sets the best interests of the child as the paramount consideration, ${ }^{22}$ section 234 of the Act provides a great step toward achieving the best interests of a child as it is now possible through a post-adoption contract to

... [M]inimise the child's loss of relationships ... [as well as] maintain and celebrate the adopted child's connections with all the important people in his or her own life, and ... allow children to resolve losses with truth, rather than fantasy. 23

Adoption enables children to grow up in a family setting which in Louw's opinion '... provides a child with a constitutionally entrenched form of care and protection that is unsurpassed by any other form of permanent placement in securing stability in child's life. ${ }^{24}$ Louw has previously expressed the hope of how '[t]he possibility of ensuring contact with a child after adoption may significantly improve the

There are countless dedicated websites and members of society however, that believe what is purported in publications, such as the results released by American Child Welfare, amount to mere propaganda in order to increase the utilisation of adoption.

20 n 9 above.

21 n 9 above.

22 Entrenched in s 28 of the Constitution.

23 n 7 above, 499.

24 A Louw 'Adoption of children' in Boezaart (n 3 above) 133. 
chances of a parent making a child available for adoption. ${ }^{25}$ One would thus think another important advantage South Africa will see in the introduction of open adoption practices is that it will contribute to an increase in the use of adoption as an alternative placement for children in need of care and protection.

An interview was conducted with Jeanie Lucas, ${ }^{26}$ who is the senior project officer of adoption, family records and post care in the government department for families and communities of South Australia. When put to her whether post-adoption contracts ${ }^{27}$ have encouraged the use of adoption and as a result caused an increase in the number of adoptions concluded in Australia, she made the following remark:

We have no research on this in our State, but it would seem that it has had no or negligible effect. A post adoption arrangement is seen as a normalised part of the adoption process in the child's best interest and is not seen as a 'sweetener' or an added extra.

The issue of grief and loss as addressed in the counselling process with the child's birth parents is a significant part of the work; the post adoption arrangement is approached as a part of the process and birth parents are presented with the idea that a post adoption arrangement carries its own challenges and is not a mechanism to alleviate grief and loss, and indeed could present challenges that add to it.

Fehlberg, ${ }^{28}$ a respected professor at Melbourne Law School, agrees that although the majority of adoptions taking place are now open, this has made no difference to the number of adoptions concluded in Australia. She stated further that birth mothers actually tend to withdraw from the adoption family over time. ${ }^{29}$ Carney, professor of law at the University of Sydney, pointed out that overall, open adoption has been very successful in the advancement of the human right to identity, in that the child is able to grow up informed about his or her biological background and any other information the parties wish to convey, such as the circumstances which led to the adoption. 30

It would seem therefore that Louw's hopes that the introduction of open adoption practices will see an increase in adoptions within South Africa may not come to fruition. In Australia where the utilisation of adoptions has been remarkably low, statistics released

A Louw 'Adoption of children' in Boezaart (n 3 above) 150.

E-mail from J Lucas on 26 August 2010.

Or 'adoption plans' as it is commonly known in Australia.

E-mail from B Fehlberg on 26 August 2010.

The withdrawal may take place for a range of reasons, such as the fact that since a post-adoption agreement is not enforceable, the birth parent is totally reliant upon the good will of the adoptive parents. For many birth parents, restricted contact to the child can be very painful and emotionally challenging.

30

Email from T Carney on 25 August 2010. 
as current as February $2010^{31}$ seem to support Ms Lucas's submission. ${ }^{32}$ Then again, adoption in Australia as previously pointed out, has had a tortured and painful history. It remains to be seen then, whether the introduction of open adoption practices by way of section 234 of the Children's Act shall have any effect on the increase in utilisation of the adoption process.

While no averment can be made that all problems faced in adoption will be solved under an open adoption plan, it is clear that open adoption addresses some very basic dilemmas and offers a psychologically healthier way in handling the needs of the individuals involved.

\section{The disadvantages of open adoption practices}

One of the major disadvantages encountered occurs as a result of the lack of provision of formal procedures and judicial enforceability with regards to post-adoption contracts. In numerous countries no remedy is available in cases where a party to an open adoption plan fails to comply with the terms agreed to. The lack of enforceability thus allows any party to freely depart from the terms of a post-adoption agreement, without suffering any legal consequences.

It is for this reason that section 167(1)(a) of the Adoption Act 2009 of Queensland, for example, proves problematic. In terms thereof, parties may very well consent to an adoption plan in conjunction with the adoption order; however the same provision does not give the adoption plan any legal force. Without judicial enforcement, how are parties to ensure that the plan is indeed complied with? At best, the parties may have agreed in the contract to refer any dispute to an alternative dispute resolution practice.

Logically, this is problematic to those birth parents who gave their child up for adoption with the promise of post-adoption contact. ${ }^{33}$ The lack of judicial enforceability of such agreements may certainly encourage coercion of birth parents' in relinquishing their parental rights and responsibilities with no intention on the part of the adoptive parents of ever fulfilling the terms set out in the informal contract. 34

Section 234(6)(a) of the Children's Act expressly states however, that a post-adoption agreement shall have affect once it is made an

31 The statistics evidence that since the late 1990s the numbers of adoption have fluctuated from year to year, but remained relatively stable at around 400 to 600 children per year.

32 Higgins 'Impact of past adoption practices: Summary of key issues from Australian research' (2010) Melbourne: Australian Institute of Family Studies 2.

33 n 7 above, 500.

34 As above. 
order of court. As a formal order of court the parties involved are protected should any person to the agreement not comply with the terms they have agreed to. The Act also enables the contract to be amended or terminated solely by an order of court should either of the parties later feel it is in the child's best interests to do so.

Another major struggle, which has arisen following the advocating of open adoption practice, concerns the exchange of information. In the UK for example, contemporary adoption practice encourages candid disclosure of medical information to adoptive parents. However, medical professionals have pointed out the struggles they face in situations where adoptive parents wish to have access to information regarding the birth parents in order to ascertain the child's medical history; but the birth parents do not wish to disclose any information at all. 35

In cases such as these, one is faced with the difficulty of balancing the right a birth parent has to confidentiality, with the need of the adoptive parent to be fully informed with regards to the child he or she will have to parent. One could even argue that the exchange of information would be in the best interests of the child since the adoptee benefits from being parented by a person who understands the child's needs and is aware of the adoptee's medical history. Therefore the right to confidentiality competes with the rights of the child too.

As open adoption practice becomes increasingly utilised in South Africa, our welfare workers may face the same difficulties in practice. The judiciary will no doubt sooner or later be required to make decisions concerning the challenges of balancing the constitutionally entrenched right to privacy, ${ }^{36}$ with the interests of the adoptive parents and adopted child to be informed-keeping in mind that our Constitution requires that the best interests of the child be paramount at all times. ${ }^{37}$

In 2003 a UK High Court judged that a local authority adoption agency fell below the reasonable standard of care when it failed to provide sufficient information about a child's potential behavioural difficulties to adoptive parents. ${ }^{38}$ This case highlights the difficulty for social workers in determining where to draw the line with regard to protecting the confidentiality of the birth family. Perhaps this court's ruling lends a solution for our courts in future, ${ }^{39}$ since such a

n 9 above.

Sec 14 of the Constitution.

$\mathrm{Sec} 28(2)$ of the Constitution.

n 9 above.

'When the courts are required to interpret any right under the Bill of Rights, it must consider foreign law' - sec 39(c) of the Constitution. 
ruling surely favours the best interests of the child and thus reiterates the best interests rule in section 28 of the Constitution.

Another matter of dispute was settled by the UK court of appeal: The court had to deal with the delicate question as to how far the court can or should go in imposing on adoptive parents obligations which they may be reluctant to assume voluntarily. ${ }^{40}$ The court of appeal stated unequivocally in its judgement that since the birth parents parental rights and responsibilities were extinguished by the operation of law when the adoption was concluded, it is the adoptive parents who make the decisions as to what they deem to be in the child's best interests, since for all purposes, they are the child's legal parents. The court further held that the defence relied upon by the birth parent - that they had a right to family life; does not apply once an adoption order is granted. ${ }^{41}$ The court therefore found that it is extremely unusual to place upon the adoptive parents obligations which they are unwilling to assume - the court therefore found in favour of the adoptive parents.

\section{A critical analysis of section 234 of the Children's ${ }^{42}$ Act}

The exact wording of the section reads as follows:

(1) The parent or guardian of a child may, before an application for the adoption of a child is made in terms of section 239 , enter into a post-adoption agreement with a prospective adoptive parent of that child to provide for:

(a) communication, including visitation between the child and the parent or guardian concerned and such other person as may be stipulated in the agreement; and

(b) The provision of information, including medical information, about the child, after the application for adoption is granted.

(2) An agreement contemplated in subsection (1) may not be entered into without the consent of the child if the child is of an age, maturity and stage of development to understand the implications of such an agreement.

(3) The adoption social worker facilitating the adoption of the child must assist the parties in preparing a post-adoption agreement and counsel them on the implications of such an agreement.

Oxfordshire County Council $v X$ and others [2010] 2 FCR 355.

[2010] 2 FCR 355 at 368.

Hereinafter referred to as 'the Act'. 
(4) A court may, when granting an application in terms of section 239 for the adoption of the child, confirm a post-adoption agreement if it is in the best interests of the child.

(5) A post-adoption agreement must be in the prescribed format.

(6) A post-adoption agreement:

(a) takes effect only if made an order of court;

(b) may be amended or terminated only by an order of court on application:

(i) by a party to the agreement; or

(ii) by the adopted child.

The above legislation therefore only permits parties to conclude a post-adoption agreement at a specific time, that being before an adoption order is granted in terms of section 239 of the same Act. By operation of law, once an adoption order is granted all parental rights and responsibilities belonging to the birth parents are extinguished and are vested in the adoptive parents.

As pointed out in a UK court of appeal: It is rather unusual to impose obligations upon the adoptive parents once an adoption order has been granted; particularly obligations which they are reluctant to voluntarily assume. ${ }^{43}$ It is therefore not irrational to expect the parties to come to a decision as to whether they would like to conclude a post-adoption agreement before the adoption is granted, as you cannot expect adoptive parents to consent to undertake duties once they have attained full parental rights and responsibilities of the child concerned.

Before the inclusion of section 234 of the Act, academics questioned whether post-adoption agreements would be precluded from parties to informal adoptions. ${ }^{44}$ An informal adoption refers to those arrangements commonly made within black communities. The practice entails an informal arrangement to the effect that the child is 'adopted' by relatives or non-relatives, while maintaining links with the biological family, the child is then eventually returned to the biological family in his or her late teens or early adulthood.

Despite the fact that an adoption is only possible in terms of a statutorily prescribed court order, ${ }^{45}$ South African courts have in certain instances also given recognition to informal adoptions concluded within indigenous communities. ${ }^{46}$ Kewana $v$ Santam Insurance Co Ltd ${ }^{47}$ as well as Metiso v Padongeluksfonds ${ }^{48}$ are two

Gagne v Canada (Correctional Service) 20102 FCR 355.

A Louw 'Open adoptions: Panacea or Pandora's Box?' (2003) De Jure 274.

As prescribed in sec 239 of the Children's Act.

Due to the fact that adoption is still an alien concept in some of these communities.

$47 \quad 19934$ SA 771 (TKA).

$48 \quad 20013$ SA $1142(\mathrm{~T})$. 
such cases: The courts held that '... the child concerned was validly adopted in terms of customary law and was therefore entitled to compensation for the loss of support resulting from the negligent killing of the child's adoptive parent, as would be the position if a formal adoption had been concluded. 49

However, since section 234(1) of the Act makes specific reference to formal adoptions concluded in terms of section 239 of the Act only, it is clear the statute does in fact preclude parties to informal adoption arrangements made in terms of customary law.

A rather unfortunate limitation however is placed upon prospective parties to a post-adoption agreement, in that section 234(1)(a) and (b) of the Act has the effect that such agreement must provide for communication and the provision of information. Bearing in mind the general rules regarding the interpretation of statutes, every word must be considered by it is ordinary meaning and it cannot be assumed that the legislature used words carelessly or frivolously.

It therefore seems that where parties wish to conclude such an agreement in terms of section 234 of the Act, they are obliged to make provision for both communication and information with regard to the child, as the legislation does not provide for it in the alternative. Should parties to the agreement wish to make provision for the exchange of information regarding the child to the exclusion of any terms providing for communication, ${ }^{50}$ such agreement shall not be enforceable, as they would be unable to make it an order of court in terms of section $234(6)$ of the Act.

\section{Conclusion}

Open adoption is certainly a most welcomed concept for adoptions in modern society. The post-adoption agreement specifically, should prove to be a great step forward in the quest to better suit the needs of each individual child as required on a case by case basis. While the South African provision still has its limitations, the flexibility now afforded to parties to an adoption will certainly assist the court in granting an order which is tailor made for the needs and best interests of the adopted child.

Section 234 of the Act should prove to be a great advantage for older children going through an adoption process, as it allows the child to maintain significant relationships already in existence prior to the adoption order. Whether this provision will be greatly utilised by parties, to which a baby is the subject of the adoption, remains to be seen. 
It is vital to keep in mind that post-adoption agreements should not be used to coerce a birth parent to make his or her child adoptable, but rather it should be used as a tool in the adoption process which is available to the parties to allow them to reach a plan which is in the best interests of that child. Our courts must be careful to remain mindful of this. An open adoption approach presents its own challenges and therefore should not be agreed to lightly. 